DOI: $10.17805 /$ trudy.2018.4.10

\title{
СОВРЕМЕННЫЕ ИНТЕРАКТИВНЫЕ СРЕДСТВА В ПРОЦЕССЕ ОБУЧЕНИЯ ИНОСТРАННОМУ ЯЗЫКУ В ШКОЛЕ
}

\author{
М. К. Иванова \\ Московский гуманитарный университет
}

\begin{abstract}
Аннотация: В статье рассмотрена необходимость применения новых образовательных технологий в процессе обучения, в целом, и использование интерактивных и информационных технологий на занятиях по иностранному языку, в частности. Акцент сделан на особенности применения интерактивной доски (Smart Boards) при обучении иностранному языку.
\end{abstract}

Ключевые слова: иностранный язык; интерактивные технологии; информационные технологии; интерактивная доска; образовательные технологии

\section{CONTEMPORARY INTERACTIVE MEDIA IN THE PROCESS OF TEACHING A FOREIGN LANGUAGE AT SCHOOL}

M. K. Ivanova

Moscow University for the Humanities

Abstract: The article considers the need to use new educational technologies in the teaching process in general, and using interactive and information technologies in foreign language classes, in particular. The emphasis is made on the peculiarities of using the interactive whiteboard (Smart Boards) in teaching a foreign language.

Keywords: foreign language; interactive technologies; information technologies; interactive board; educational technologies

Проблема мотивации обучения иностранному языку во все времена была одной из самых в образовательном процессе. Создание основы для формирования интереса к совершенствованию владения изучаемым иностранным языком сформулировано в качестве цели в ФГОС, принятых в 2010 г. Для реализации этой цели необходимо наличие современной информационно-образовательной среды, что означает необходимость владения информационными технологиями, как педагогов, так и обучающихся. Умение использовать средства информационных технологий прописано в ФГОС основного общего образования 2015 г., в приказе Министерства образования и науки РФ от 17 декабря 2010 г. № 1897. Достижение этих целей наиболее эффективно возможно за счёт использования интерактивных ме- 
Научные труды Московского гуманитарного университета 2018 № 4

тодов обучения с использованием информационных технологий. Привлекательность использования информационных технологий в современной образовательной организации заключается ещё и в том, что учебный материал обучающимся преподносится наиболее красочно и интересно.

Практическая направленность владения иностранным языком является целью образовательных учреждений при обучении иностранному языку. Для реализации этой цели очень важным является коммуникативная деятельность, которая достигается за счёт активизации деятельности каждого обучающегося в процессе обучения. Внедрение современных интерактивных технологий имеет значительное влияние на систему образования. Необходимость применения новых образовательных технологий в обучении, а также актуальность использования интерактивных технологий на занятиях, в особенности по иностранному языку обоснована А. Р. Барановым, Г. Р. Еремеевой, Р. А. Ладнер. Причём, в настоящее время широкое применение в образовательной практике получили такие интерактивные средства обучения как: интерактивная доска, использование интернет-ресурсов, электронных проектов, презентаций Power Point (Баранова, Еремеева, Ладнер, 2016).

Э. Г. Азимов и А. Н. Щукин интерактивные средства обучения определяют как средства обучения, связанные с использованием информационно-компьютерных технологий (Азимов, Щукин, 2009). Интерактивность предполагает, прежде всего, непрерывное взаимодействие учителя и обучающегося в процессе обучения. Интерактивность существует и в процессе компьютерной программы с пользователем-человеком в ходе работы (Вовчаста, 2013, Электр. ресурс). А. Р. Баранова, Г. Р. Еремеева, Р. А. Ладнер считают, что понятие интерактивных технологий в настоящее время неизменно ассоциируется с информационными технологиями, что подразумевает использование выше перечисленных информационно-образовательных ресурсов (Баранова, Еремеева, Ладнер, 2016).

М. В. Чилингарян, рассматривая интерактивные информационные средства, выделяет электронные проекты, которые используются при проектном обучении (Чилингарян, 2016: Электр. ресурс). Л. Х. Цеева и Р. К. Симбулетова также исследуют понятие проектного обучения, как основу практико-ориентированной подготовки при изучении иностранного языка (Цеева, Симбулетова, 2014). Они утверждают, что существует прямая зависимость между мотивацией, активностью учащихся и проектной деятельностью. Под проектной деятельностью понимается такой тип развивающей деятельности, которая основывается на выполнении творческих учебных проектов для усвоения знаний. М. В. Чилингарян описывает электронные проекты как проекты, созданные обучающимися на основе мультимедиа технологий (Чилингарян, 2016: Электр. ресурс). Делается вывод о том, что 
данная работа требует от обучающегося исследовательской деятельности, анализа и обработки найденной информации, создания и презентации проекта другим членам образовательного процесса. Использование электронных проектов в ходе обучения иностранному языку ориентировано на практический результат, значимый для обучающегося. Учителю стоит помнить, что его задача в ходе работы обучающимися над проектом заключается в консультировании, оказании помощи отстающим детям, поддержании рабочей атмосферы в классе, если проект создаётся на уроке и оценке творческой деятельности на каждом этапе выполнения проекта.

Ещё одним средством повышения мотивации обучающихся при изучении иностранного языка является использование на уроках интерактивной доски. По мнению М. В. Чилингарян, преимуществом этого средства является то, что восприятие, анализ и передача информации обучающимся происходит быстрее за счёт того, что задействуются все каналы восприятия информации (Чилингарян, 2016: Электр. ресурс). Существует три основных канала для восприятия информации, а именно: зрение, слух и кинестетика. В зависимости от доминирования того или иного способа поступления и переработки информации можно выделить визуальный, аудиальный и кинестетический способ восприятия информации. Каждый человек, по мнению Р. Бендлера и Д. Гриндера, обладает всеми тремя способами восприятия, но предпочитает использовать с максимальной нагрузкой только один, который называется ведущим способом восприятия информации (Гриндер, Бендлер, 1995). Благодаря основному способу восприятия, осуществляется максимальный доступ к информации. Учителю необходимо выработать стиль обучения с учетом ведущего способа восприятия информации учащимися. При работе с интерактивной доской такая необходимость отпадает. Это обусловлено сочетаемостью разных стилей обучения при использовании интерактивной доски в обучении иностранному языку, таких как: визуальные, слуховые и кинестетические. Благодаря этому погружение в языковую среду происходит легче, повышается интерес обучающихся к предмету за счёт творческих заданий, которые минимизируют нервную нагрузку, развиваются различные виды коммуникативных умений.

Г. В. Романова отмечает ряд преимуществ использования интерактивной доски, как средства информационной технологии, а именно: интенсивность процесса обучения, высокая степень аутентичности, работа с доской более чем реализует принцип наглядности, создание новой обучающей среды, такой, например, как Московская Электронная Школа (МЭШ), где собраны электронные пособия и учебники и более тысячи готовых сценариев уроков. Они прошли модерацию и отобраны специалистами в соответствии с требованиями к содержанию и форме. В них заложена возможность взаи- 
Научные труды Московского гуманитарного университета 2018 № 4

модействовать с виртуальными образами и моделями изучаемых лингвистических явлений. Присутствует высокий уровень интерактивности, возможность автоматизированного контроля и учёта результатов усвоения материала обучающимися, что позволяет сделать оценивание более объективным, игровая форма проведения занятия с использованием доски повышает мотивацию к обучению (Романова, 2015ab).

Интерактивная доска может иметь положительное влияние на преподавание. При помощи такой доски можно использовать веб-ресурсы в обучении всего класса, а также сделать класс нелинейным за счёт возможности связывать объекты (компьютер учителя - интерактивную доску - планшет ученика). К примеру, на уроке английского языка часть обучающихся могут обсуждать языковые явления, а другая часть - писать тест. Происходит дифференциация обучения в рамках одного учебного коллектива, класс становится нелинейным.

Интерактивная доска позволяет преподавателям использовать мультимедийные материалы, которые помогают им представить и объяснить различные концепции, к примеру, разницу между временами в английском языке. Доска может сохранить то, что пишет учитель, включая примечания, сделанные во время урока, уменьшая дублирование и облегчая пересмотр для будущего использования. Это позволяет учителям предоставлять достоверные материалы и информацию через текст, изображения, звуки, видео сегменты и анимацию, так как используется вместе с новой образовательной средой МЭШ, где весь образовательный контент хранится в библиотеке после прохождения модерации. Также использование МЭШ при работе с интерактивной доской позволяет преподавателям обмениваться и повторно использовать материалы, уменьшая рабочую нагрузку.

Обучение с использованием интерактивной доски повышает вовлеченность учащихся больше - более, чем обычное обучение всего класса, так как способствует участию учащихся, давая им возможность взаимодействовать с материалами, методы обучения включают в себя визуальное, а не устное обучение, поддерживается множество различных стилей обучения. Повышение мотивации рассматривается как ключевое преимущество интерактивной доски. Мотивация в контексте «класс» измеряется стремлением учащегося участвовать в деятельности Smart Board (Al-Faki, 2014). На уроках английского языка интерактивная доска может применятся на различных этапах урока, при обучении различным видам речевой деятельности. К примеру, при обучении чтению используются такие приёмы, как установление соответствий, восстановление деформированного текста, выделение необходимой информации. Коммуникативную ценность при обучении говорения имеют задания: незаконченное предложение, соотно- 
шение реплик в диалоге. Для введения новой лексики используется распределение на группы особенно актуально при изучении темы «Countable/ Uncountable nouns», заполнение пробелов. При отработке грамматического материала можно использовать приёмы: убери лишнее, найди ошибку, создание схем, часть информации можно скрыть, чтобы обучающиеся сами дополнили схему.

Однако наряду с положительными сторонами использования интерактивной доски или другими словами Smart Board встречаются и сложности, с которыми приходится сталкиваться учителям. Учителя нуждаются не только в обучении компьютерной грамотности, а также в педагогическом применении этих навыков для улучшения преподавания и обучения. Часто учителя сталкиваются с техническими проблемами при работе в технологически интегрированном классе. В моей практике встречались такие проблемы, как нерабочая электронная ручка (стилус), из-за которой не было возможности сделать записи и пометки на доске в ходе урока, отсутствие связи между интерактивной доской и компьютером, отставания в интерактивности между движением рук и доски, а также в солнечную погоду солнечный свет влияет на визуальный элемент -обучающиеся не могут видеть, что находится на доске.

А. Э. Токтаньязова, исследуя использование новых информационных технологий в процессе обучения иностранным языкам, особое внимание уделяет обучению иностранному языку с использованием интернет-ресурсов. Интернет в настоящее время уже не источник знаний для обучающихся, а организатор процесса исследования, поиска, анализа информации, создания творческих проектов в осуществлении деятельностного подхода к образованию (Токтаньязова, 2007).

По мнению А. Э. Токтаньязовой, обучение английскому языку или любому другому иностранному языку при помощи интернет-ресурсов реализует такой принцип обучения как принцип дифференциации, то есть обучающиеся занимаются самообучением в индивидуальном плане, учитываются индивидуальные периоды подъёма и спада работоспособности, что отсутствует на традиционном уроке. Также реализуется принцип межличностного общения. Переписываясь с носителем языка, обучающиеся могут сами выбрать себе собеседника по интересам. Принцип вариативности, который заключается в том, что обучающийся может выбрать источник информации, сравнивая их. Принцип кулътуросообразности осуществляется за счёт общения с носителем языка в режиме реального времени, что обеспечивает культурный контекст изучения языка. Ознакомление с культурой другой страны проходит легче и интереснее в общении, чем через знакомство с культурой другой страны путём прочтения «сухой» информации в книге (там же). 
Научные труды Московского гуманитарного университета 2018 № 4

М. В. Чилингарян и Г. В. Романова упоминают о том, что одним из эффективных средств работы обучающихся с Интернет-ресурсами являются каталоги, которые помогут найти необходимую актуальную информацию, соответствующую возрастным особенностям, выполнить задание, избежав информации, которая может навредить психике ребёнка. (Чилингарян, 2016, Электр. ресурс; Романова, 2016). Использование интернет-ресурсов непосредственно в ходе урока является неординарной и увлекательной формой работы, но требующей от учителя тщательного планирования видов деятельности обучающихся в ходе урока. (Романова, 2016). Одним из самых распространённых вопросов, из-за которых педагог обращается к возможностям сети Интернет, является подготовка к единому государственному экзамену по иностранному языку. В условиях наличия лингофонного кабинета, оборудованного компьютерами с возможностью выхода в интернет, использовать интернет-ресурсы можно прямо на уроке. Существует ряд сайтов, содержащих аутентичные аудио и видео материалы, тексты для чтения, игры, которые можно использовать в ходе урока. К примеру, тексты можно использовать для отработки и проверки навыков поискового чтения, так как после прочтения предлагается пройти небольшой тест на понимание прочитанного и сразу получить независимую компьютерную оценку.

Среди интерактивных информационных технологий также рассматривается проведение уроков с использованием презентаций Microsoft Power Point, которые дополняют традиционное обучение английскому языку (Захарова, 2003). По мнению М. В. Чилингарян, в арсенале данной программы есть достаточное количество инструментов для эффективной подачи учебного материала. Автор выделяет инструменты, которые используют для предъявления информации отдельными фрагментами, представить дополнительный материал для отстающих или наоборот продвинутых обучающихся, создать на уроке соответствующую эмоциональную атмосферу. Грамотно созданная презентация позитивно влияет на интерес обучающихся, но стоит отказаться от чрезмерной увлечённостью привлекательностью создаваемой презентации, необходимо найти золотую середину между подаваемым материалом и сопровождающими его эффектами (Чилингарян, 2016).

На практике презентации решают проблему использования наглядного материала. Обучая иностранному языку использование презентаций как никогда подходит для объяснения грамматического материала, так как есть возможность создать схемы, таблицы графики, а при помощи анимации наглядно объяснить, к примеру, объясняя разницу между Past Simple,Present Perfect, Past Perfect.

Общеобразовательная школа сегодня немыслима без разнообразного и широкого применения технических средств обучения. Такие средства обу- 
чения обладают большой информативностью, достоверностью, позволяют проникнуть в глубину изучаемых явлений и процессов, повышают наглядность обучения, способствуют интенсификации учебно-воспитательного процесса, усиливают мотивацию у обучающихся, что безусловно важно при обучении иностранному языку. Поэтому применение интерактивных средств обучения на уроках иностранного языка способствует совершенствованию учебно-воспитательного процесса, повышению эффективности педагогического труда, улучшению качества знаний, умений, навыков обучающихся. Интерактивные доски органично войдут в образовательный процесс при условии активной постоянной работы учителя, накопления им методических идей, разработок и совершенствования навыков работы с современным оборудованием.

\section{СПИСОК ЛИТЕРАТУРЫ}

Азимов, Э. Г., Щукин, А. Н. (2009) Новый словарь методических терминов и понятий (теория и практика обучения языкам). М. : ИКАР. 448 с.

Баранова, А. Р., Еремеева, Г. Р., Ладнер, Р. А. (2016) Интерактивные технологии на занятиях по иностранному языку // Казанский педагогический журнал. № 5 (118). С. 164-168.

Вовчаста, Н. Я. (2013) Роль интерактивных технологий на занятиях по иностранному языку [Электронный ресурс] // Сибак. URL: http://sibac.info/ conf/pedagog/xxiv/31482 (дата обращения: 20.06.2018).

Гриндер, Д., Бендлер, Р. (1995) Из лягушек - в принцы. Воронеж : МОДЭК. 240 с.

Захарова, И. Г. (2003) Информационные технологии в образовании. М. : Издательский центр «Академия». 192 с.

Романова, Г. В. (2015а) Интерактивная доска как экранное техническое средство обучения иностранному языку для реализации современного метода работы с иноязычной информацией // Педагогическое образование в России. № 9. С. 28-32.

Романова, Г. В. (2015b) Применение экранных технологий при обучении иностранному языку в средней общеобразовательной школе // Педагогическое образование в России. № 8. С. 41-45.

Романова, Г. В. (2016) Развитие иноязычной грамматической компетенции обучающихся 9-х классов с учетом их психолого-возрастных и индивидуальных особенностей (на основе применения интерактивной доски) // Педагогическое образование в России. № 2. С. 189-194.

Токтаньязова, А. Э. (2007) Проект «Интернет в обучении иностранному языку» // Новые технологии. № 3. С. 200-202. 
Чилингарян, М. В. (2016) Использование информационно-образовательных технологий на уроках английского языка [Электронный ресурс] // Научно-методический электронный журнал «Концепт». № S12. URL: http:// e-koncept.ru/2016/76148.htm. (дата обращения: 05.06.2018).

Цеева, Л. Х., Симбулетова, Р. К. (2014) Аспекты проектного обучения на примере иностранного языка // Вестник Адыгейского государственного университета. Серия 3: Педагогика и психология. № 3 (143). С. 115-119.

Al-Faki, I. M. (2014) Difficulties Facing Teachers in Using Interactive Whiteboards in Their Classes // American International Journal of Social Science. Vol. 3. No. 2. C. 136-158.

Дата поступления: 15.08.2018 2.

Иванова Мария Константиновна - магистрант кафедры педагогики и психологии высшей школы Московского гуманитарного университета. Адрес: 111395, Россия, г. Москва, ул. Юности, д. 5 . Тел.: +7 (499) 374-74-59. Эл. адрес: Ivanovamasha1993@yandex.ru. Научный руководитель - д-р пед. н., проф. В. А. Ситаров.

Ivanova Maria Konstantinovna, Graduate Student, Department of Pedagogy and Psychology of Higher School, Moscow University for the Humanities. Postal address: 5, Yunosti St., Moscow, Russian Federation, 111395. Tel.: +7 (499) 37474-59. E-mail: Ivanovamasha1993@yandex.ru. Scientific Adviser- Sitarov V. A., Doctor of Pedagogy, Professor.

\section{Для цитирования:}

Иванова М. К. Современные интерактивные средства в процессе обучения иностранному языку в школе [Электронный ресурс] // Научные труды Московского гуманитарного университета. 2018. № 4. URL: http://journals. mosgu.ru/trudy/article/view/814 (дата обращения: дд.мм.гг.). DOI: 10.17805/ trudy.2018.4.10 